Adıyaman Üni. Sağlık Bilimleri Derg, 2017; 3(3):617-624

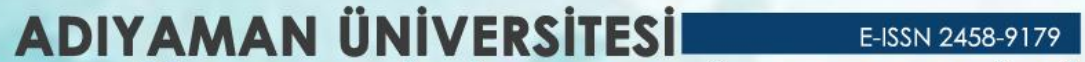 SAĞLIK BÍLIMLERI DERGISI \\ dergipark.gov.tr/adiyamansaglik
}

\section{Derleme/Review \\ Pilonidal Sinüs Tedavisinde Kristalize Fenol}

Ferhat $\mathrm{CAY}^{1}$, Burhan Hakan KANAT ${ }^{2}$, Mustafa GIRGIN ${ }^{3}$

${ }^{1}$ Midyat Devlet Hastanesi, Genel Cerrehi Klini ği, Mardin

${ }^{2}$ Elazı̆̆ Eğitim ve Araştırma Hastanesi, Genel Cerrehi Kliniği, Elazıg

${ }^{3}$ Firat Üniversitesi, Tıp Fakültesi, Genel Cerrahi AD, Elazıg

\section{Özet}

Pilonidal sinüs hastalığı daha sıklıkla genç-erişkin erkeklerde görülür. Tedavisinde uygulanan birçok cerrahi tedavi yöntemi ve bunların modifiye edilmiş uygulamaları mevcuttur. Ayrıca hastalığın cerrahi dışı yöntemlerle tedavisi de sürekli gündemdedir. Bu yazıda son yıllarda cerrahlar arasında ilgi uyandıran kristalize fenol yöntemini literatür eşliğinde kısaca sunmayı amaçladık.

Anahtar kelimeler: Pilonidal Sinüs, Kristalize Fenol,

\section{Summary}

\section{Crystallized Phenol in Pilonidal Sinus Therapy}

Pilonidal sinus disease is more common in younger-adult males. There are many surgical treatment modalities and their modifications applied in the treatment. In addition, non-surgical treatment of the disease is always on the agenda. In this article we aimed to present briefly in recent years.

Keywords: Pilonidal Sine,Crystallized Phenol,

\section{Yazışmadan Sorumlu Yazar}

Ferhat ÇAY

Midyat State Hospital, Department of General Surgery, Mardin, TURKEY.

Tel : + 0904824621106

Email: cayferhat@gmail.com
DOI: 10.30569/adiyamansaglik. 375103

\begin{tabular}{ll}
\hline Geliş Tarihi: & 04.01.2018 \\
\hline Kabul Tarihi: & 11.01 .2018
\end{tabular}




\section{Giriş}

Pilonidal sinüs hastalığı daha çok genç erişkinleri etkilemektedir. Erkeklerde daha sık görülmesine rağmen tarihte ilk kez 1833 yılında Herbert Mayo tarafından, bir kadın hastada sakrokoksigeal bölgede kıl içeren sinüs olarak tarif etmiştir $(1,2)$. Kısa bir süre farklı şekillerde isimlendirilmişse de Hodges 1880 yılında Latince k1l anlamına gelen 'pilus' ve yuva anlamına gelen 'Nidus' kelimelerini birleştirerek 'pilonidal' kelimesini oluşturmuştur $(3,4)$.

Hastalık tariflendiği günden itibaren tartışmalara neden olmuştur. Gerek etiyolojisi gerekse de tedavisi pek çok kez yazılmış ve kesin sonuçlar elde edilememişse de etiyoloji konusu pek uzun sürmemiştir. Artık neredeyse tüm cerrahlar hastalığın edinsel olduğu konusunda hemfikirdir (5). Ancak rota tedavi açısından aynı yolu izlememiştir. Tariflendiğinden bu güne nerdeyse iki asır geçmesine rağmen ideal tedavi netlik kazanmamıştır (6).

Uygulanan onlarca cerrahi tedavi yöntemi ve bunların modifiye halleri dışında hastalığın cerrahi dışı yöntemlerle tedavisi de sürekli gündemde kalmıştır. Özellikle fenol uygulaması merak uyandırmış ve birçok yandaş bulmuştur (7).

Kimyasal bir madde olan fenol; pilonidal sinüs hastalığı tedavisinde likit ya da kristalize formlarda kullanılmaktadır. Sinüs içindeki kılların temizlenmesi ve küretaj sonrası içeriye sıvı fenol uygulaması ilk kez 1964 yılında Maurice ve Greenwood tarafından tanımlanmıştır (8). Sıvı yerine kristalize formunun kullanılması ve bu şekilde tedavi edilmesi ise 2004 yılında Doğru tarafından tarif edilmiştir (9). 


\section{Kristalize Fenol}

Fenol $\left(\mathrm{C}_{6} \mathrm{H}_{6} \mathrm{O}\right)$; saf halde, renksiz veya beyazdan hafifçe pembeye çalan renkte kristal katı şeklindedir (Resim 1). Fizik özellik olarak kendine has kokulu, ince, uzun, sivri, renksiz ve havada zamanla pembe renk alan billürlar veya billüri kütledir. Suda, sıvı parafinde erir; alkolde, eterde, kloroformda, gliserinde, karbon sülfürde, şahmi zeytlerde ve kalevilerde kolaylıkla erir. Erime noktası $37-41^{\circ} \mathrm{C}$, kaynama noktas $178-182^{\circ} \mathrm{C}$ ve spesifik (öz) ağırlığ $1,07 \mathrm{~g} / \mathrm{cm} 3$ tür. Saf halde renksizdir (10).

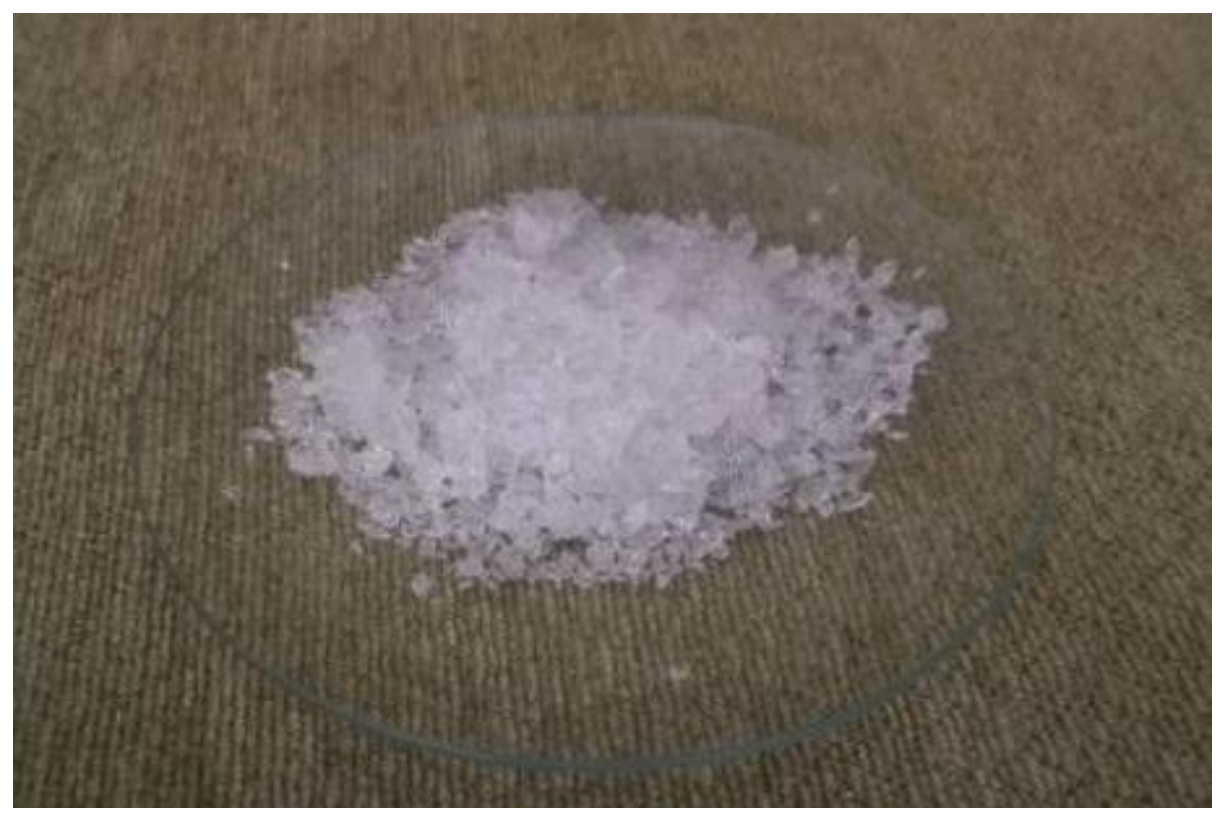

Resim 1: Kristal Fenol $\left(\mathrm{C}_{6} \mathrm{H}_{6} \mathrm{O}\right)$; katı, saf halde, renksiz veya beyazdan hafifçe pembeye çalan renktedir.

\section{Kristalize Fenol Uygulama Yöntemi}

İşlem öncesi hastaların sakrokoksigeal bölgelerinin k1l ve hijyen temizliği yapması önerilmelidir. $\mathrm{Bu}$ temizlik tıpkı cerrahi uygulanan hastalarda istenilen şekilde olmalıdır. Poliklinik şartlarında steril alan oluşturularak hastalara lokal anesteziyi takiben sinüs açıklıklarından sinüs traktının temizlenmesi ve kürete edilmesi işlemi uygulanır. Mosquito 
klempin giremeyeceği kadar küçük sinüs deliğine sahip hastalarda sinüs ağzı buna müsaade edecek kadar genişletilir. Birden fazla sinüs ağzına sahip hastalarda aynı işlem her bir sinüs ağzı için ayrı ayrı uygulanır. Uygulamaya başlarken çevre cilt dokusu sulandırılmamış, saf kristalize fenolun irritan ve yakıcı etkisine karşı antibiyotikli krem (nitrofurazon etkin maddeli bir topikal antibiyotikli krem) ile korunmalıdır. Sinüs içindeki debris ve k1llar ortamdan tamamen arındırılmalıdır (Resim 2).

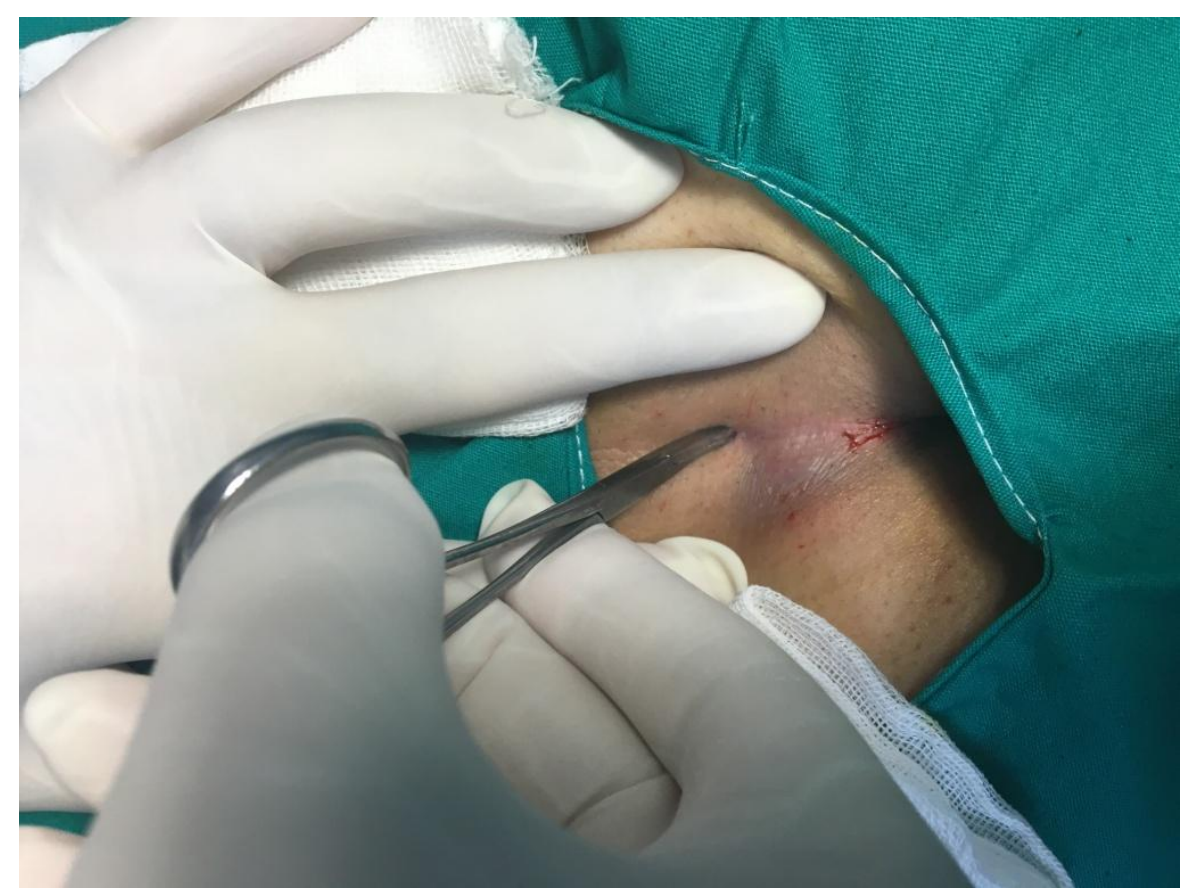

Resim 2: Sinüs içindeki debris ve kılların ortamdan tamamen arındırılması.

Kristalize fenol (C6H6O) pilonidal sinüs poşunun içine yine aynı Mosquito klemp yardımıyla tatbik edilir ve vücut sıcaklığına ulaşan kristalize fenol sıvı forma dönüşerek irritan etki sağlar.

Her bir sinüs açıklığından yaklaşık 3-5 gram kadar kristalize fenol uygulanır (Resim 3). Hastalara istirahat tedavisi verilmeyip işlerine dönmeleri tavsiye edilir. Hastalar 24 saat sonra tek bir pansuman sonrasında istedikleri zaman banyo edebilir. Hastalar üçer haftalık 
aralarla takip ve kontrol edilmektedir. Üç haftalık takibin sonunda sinüs ağzı tamamen kapanmış, akıntısı olmayan hastalar iyileşmiş olarak kabul edilir açıklığı kapanmamış ve akıntısı devam eden hastalara tekrar kristalize fenol seansı aynı şekilde uygulanmalıdır.

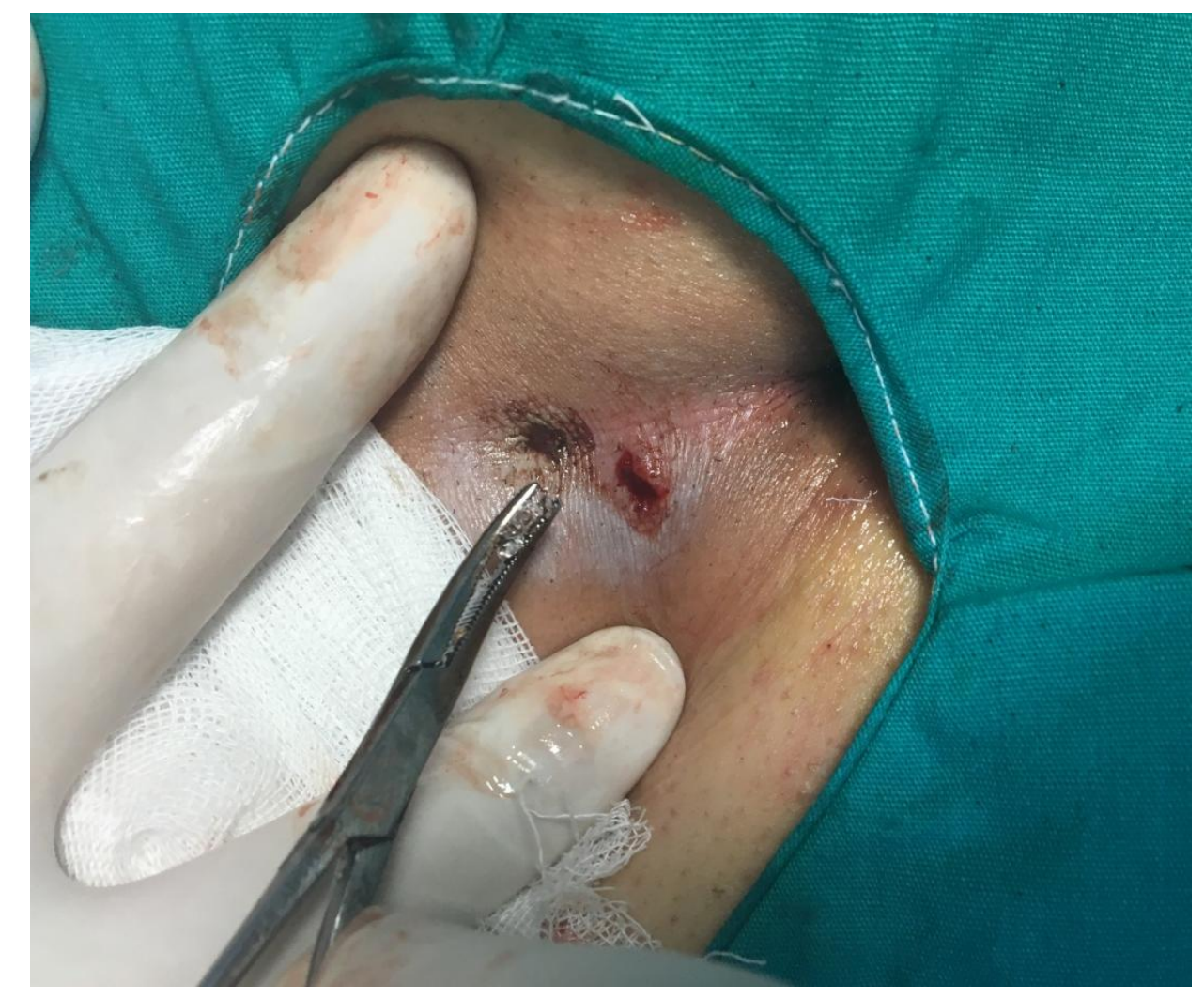

Resim 3: Sinüs açıklığından Kristalize Fenol uygulanması

\section{Sakrokoksigeal Pilonidal Sinüs Tedavisinde Uygulamalar}

01.03.2015 tarihinde Pubmed ve Google-Scholar veri tabanları ingilizce anahtar kelime ya da kelime kombinasyonları (crystallized phenol, pilonidal sinus disease) kullanılarak tarama yapıldığında ulaşılan 6 adet makalenin verileri tablo 1'de verilmiştir. 
Tablo 1. Literatürdeki Makalelerin Bulguları

\begin{tabular}{|l|c|c|c|c|c|c|c|c|c|c|}
\hline Yazar & $\begin{array}{c}\text { Yayın } \\
\text { Yıı }\end{array}$ & $\begin{array}{c}\text { Olgu } \\
\text { sayısı }\end{array}$ & Erkek & Kadın & $\begin{array}{c}\text { Ortalama } \\
\text { Yaş (yı) }\end{array}$ & $\begin{array}{c}\text { Takip } \\
\text { süresi } \\
\text { (ay) }\end{array}$ & $\begin{array}{c}\text { Toplam } \\
\text { Uygula- } \\
\text { ma } \\
\text { sayısı }\end{array}$ & $\begin{array}{c}\text { Komplika } \\
\text { syon } \\
\text { Oranı }\end{array}$ & $\begin{array}{c}\text { Nüks } \\
\text { Oranı }\end{array}$ & $\begin{array}{c}\text { Başarı } \\
\text { Oranı }\end{array}$ \\
\hline $\begin{array}{l}\text { Girgin } \\
\text { ve ark. }\end{array}$ & 2012 & 42 & 31 & 11 & 22.5 & 24 & 90 & 0 & 0 & $\% 100$ \\
\hline $\begin{array}{l}\text { Girgin } \\
\text { ve ark }\end{array}$ & 2014 & 48 & 44 & 4 & 28.7 & 22 & 97 & $\begin{array}{c}\text { Belirtil- } \\
\text { memiş }\end{array}$ & 0 & $\% 95$ \\
\hline $\begin{array}{l}\text { Aygen } \\
\text { ve ark. }\end{array}$ & 2010 & 36 & 33 & 3 & 28.9 & 54.4 & 107 & $\% 8.3$ & $\% 13.9$ & $\% 91.7$ \\
\hline $\begin{array}{l}\text { Akan ve } \\
\text { ark. }\end{array}$ & 2013 & 50 & 42 & 8 & 24.72 & 26 & 50 & $\% 12$ & $\% 12$ & $\% 88$ \\
\hline $\begin{array}{l}\text { Doğru } \\
\text { ve ark. }\end{array}$ & 2004 & 41 & 37 & 4 & 26.4 & 24 & 107 & $\begin{array}{c}\text { Belirtil- } \\
\text { memiş }\end{array}$ & $\% 5$ & $\% 100$ \\
\hline $\begin{array}{l}\text { Topuz } \\
\text { ve ark. }\end{array}$ & 2014 & 20 & 17 & 3 & 25.6 & $\begin{array}{c}\text { Belirtil- } \\
\text { memiş }\end{array}$ & $\begin{array}{c}\text { Belirtil- } \\
\text { memiş }\end{array}$ & $\begin{array}{c}\text { Belirtil- } \\
\text { memiş }\end{array}$ & \\
\hline
\end{tabular}

Konu ile ilgili ilk çalışma; 2004 yılında Doğru ve ark. (9) tarafindan bildirilmiştir. Retrospektif olarak 41 hasta ortalama 24 aylık takip süresi ile 8 ylllık deneyim sunulmuş. En düşük tek kür tedavi şansı bu çalışmada olup \%10 civarındadır. Bu çalışmaya akut hastalar da dahil edilmiş olup; buna göre kristalize fenolün akut pilonidal sinüs olgularında da etkinliği saptanmıştır.

Aygen ve ark. (11) daha önce cerrahi ya da konservatif olarak tedavi görmüş 36 nüks pilonidal sinüs olgusunda literatürdeki en yüksek takip süresine (54.4 ay) sahip çalışmayı bildirmişlerdir. $\mathrm{Bu}$ çalışmada kristalize fenolün nüks vakalarda da yüksek başarı şansı ile uygulanabileceği kanaatine varılmıştır. Bu vakalarda başarı oranı \%91.7 olarak rapor edilmiştir. Tarafımızdan yapılan iki çalışmada ise tek kür tedavi şansı ve lazer epilasyon ile birlikte etkinliği bildirilmiştir. $\mathrm{Bu}$ çalışmalarda tek uygulama ile başarı şansı \% 61.9 ile 
64.5'tir. Tedavide kıl temizliğinin başarı şansını artıracağı vurgulanmıştır. İki çalışmada toplam başarı şansı \%95'in üzerindedir $(12,13)$.

Tedavinin en önemli kriterlerinden biri olan yaşam kalitesi ise Topuz ve ark. (14) tarafindan değerlendirilmiştir. Eksizyon ve primer kapama ile kristalize fenol uygulanan 20'şer hasta karşılaştırılmış. Sonucunda; Visual Analog Skala (VAS) Değerlendirmesi, hastanede kalış süresi, işe dönüş süresi, pansuman sayısı, ilaç alımı, normal pozisyonda oturma zamanı, ağrısız zaman, spor yapma zamanı, seyahat etme zamanı, cinsel açıdan ve kozmetik olarak kristalize fenol istatistiksel olarak daha iyi bulunmuş. Buna göre kristalize fenol ile tedavi yaşam kalitesini artırmaktadır. Limberg Flep Yöntemi ile kristalize fenolün kıyaslandığı başka bir çalışmada da gerek kozmetik açıdan, gerekse de hastanede kalmayı gerektirmemesi açısından kristalize fenol tedavisi daha üstün bulunmuştur (15).

Komplikasyonlara gelecek olursa; cerrahi yöntemlere göre daha minör ve hem hasta hem de cerrah açısından daha tolere edilebilir sıkıntılarla karşılaşılabilir. Lokal anestezinin yan etkileri olabilmekle birlikte kristalize fenol uygulamasına özgü komplikasyonlar da mevcuttur. Bunlar daha çok lokal yan etkilerdir. Uygulama sırasında cilt eğer yeteri düzeyde korunmaz ise exfoliation oluşmaktadır. Ayrıca enfeksiyon ve hematom görülebilir. Literatürde exfoliation oranı \%8.3 olarak bildirilmiştir (11). Enfeksiyon ve hematom oranları ise sırayla $\% 8$ ve $\% 4$ olarak rapor edilmiştir (15).

Tedavinin başarı oranı tatminkâr düzeyde olup nüks oranı ise kabul edilebilir düzeydedir. Çalışmalarda takip süreleri içerisindeki nüks oranları $\% 0$ ile 13.9 arasında değişmektedir. Sonuç olarak; sakrokoksigeal pilonidal sinüs tedavisinde kristalize fenol uygulaması, seçilmiş vakalarda ve doğru teknikle yapıldığında en iyi tedavi yöntemlerinden biridir. Özellikle bölgenin kıl ve hijyen temizliğinin de iyi şekilde yapılmasıyla başarı şansı daha da yükselmektedir. 
Tedavinin ameliyathanede değil de poliklinik şartlarında sınırlı uyuşturma ile yapılabilmesi, hastanede yatışı gerektirmemesi gibi üstünlükleri ile tedavi için mutlaka düşünülmesi gereken bir yöntemdir. Tüm hastalara bu şans tanınmalıdır.

\section{KAYNAKLAR}

1. Mayo OH. Observations on Injuries and Diseases of the Rectum. London: Burgess and Hill; 1833.

2. Amit Khanna, John L. Rombeau. Pilonidal Disease. Clin Colon Rectal Surg. 2011 March; 24(1): 46-53.

3. Maurice BA, Greenwood RK (1964) A conservative treatment of pilonidal sinus. Br J Surg 51:510-512.

4. Hodges RM (1880) Pilonidal sinüs. Boston Med Surg J 103:485- 48.

5. de Parades V, Bouchard D, Janier M, Berger A. Pilonidal sinus disease. J Visc Surg. 2013 Sep;150(4):23747.

6. Karydakis GE. Easy and successful treatment of pilonidal sinus after explanation of its causative process. ANZ J Surg 1992;62:385-9.

7. Kanat BH, Bozan MB, Yazar FM, Yur M, Erol F, Ozkan Z. et al. Comparison of early surgery (unroofingcurettage) and elective surgery (Karydakis flap technique) in pilonidal sinus abscess cases. Ulus Travma Acil Cerrahi Derg 2014;20(5):366-370.

8. Kayaalp C, Aydin C.Review of phenol treatment in sacrococcygeal pilonidal disease.Tech Coloproctol. 2009 Sep;13(3):189-93.

9. Maurice BA, Greenwood RK (1964) A conservative treatment of pilonidal sinus. Br J Surg 51:510-512

10. Dogru O, Camci C, Aygen E, Girgin M, Topuz O. (2004) Pilonidal sinus treated with crystallized phenol: An eight-year experience. Diseases of the Colon \& Rec- tum, 47, 1934-1938.

11. Öktel NM. Farmakoloji; Lokal Anestezikler, Antiseptikler ve Dezenfektanlar, Terletici ve Ter Kesen İlaçlar, Döl Yatağı Üzerine Tesir Eden İlaçlar, Deri Hastalıklarında Kullanılan Bazı İlaçlar, Aromatik İlaçlar. Ankara Üniversitesi Eczacılık Fakültesi Yayınları No:14 Fasikül 3. Ongun Kardeşler Matbaası. Ankara 1967: $21-28$

12. Aygen E, Arslan K, Dogru O, Basbug M, Camci C. Crystallized phenol in nonoperative treatment of previously operated, recurrent pilonidal disease. Dis Colon Rectum. 2010 Jun;53(6):932-5. doi: 10.1007/DCR.0b013e3181d8283b.

13. Girgin M, Kanat BH, Ayten R, Cetinkaya Z, Kanat Z, Bozdağ A, Turkoglu A, Ilhan YS. Minimally invasive treatment of pilonidal disease: crystallized phenol and laser depilation. Int Surg. 2012 Oct-Dec;97(4):288-92.

14. Girgin M, Kanat BH. The results of a one-time crystallized phenol application for pilonidal sinus disease. Indian J Surg. 2014 Feb;76(1):17-20.

15. Topuz O, Sözen S, Tükenmez M, Topuz S, Vurdem UE. Crystallized phenol treatment of pilonidal disease improves quality of life. Indian J Surg. 2014 Feb;76(1):81-4.

16. Akan K, Tihan D, Duman U, Özgün Y, Erol F, Polat M. Pilonidal sinüs tedavisinde cerrahi Limberg flep yöntemi ile kristalize fenol uygulamasının retrospektif karşılaştırılması. Ulusal Cer Derg 2013; 29:162-166. 